\title{
USE OF HYDROGEN PEROXIDE AND PEROXYL RADICALS TO INDUCE OXIDATIVE STRESS IN NEURONAL CELLS
}

\author{
Sana Ben Othman and Tomio Yabe
}

United Graduate School of Agricultural Science, Gifu University, 1-1 Yanagido, Gifu 501-1193, Japan

\begin{abstract}
Reactive oxygen species accumulation has an established role in aging-related diseases, particularly in neurodegenerative diseases; however, its role remains incompletely elucidated. Considering the increasing elderly population, especially in developed countries, proper management of aging-related diseases has become essential and, research on antioxidant therapies is flourishing. Neuronal cells are at the center of oxidative stress research, where studies are being conducted to develop preventive or curative treatments against neurodegenerative diseases such as Alzheimer's disease and Parkinson's disease. A panel of pro-oxidants can be used to induce oxidative damage in neuronal cells in vitro. In this mini-review, the use of hydrogen peroxide and 2,2' - azobis (2-amidinopropane) dihydrochloride -generated peroxyl radicals to induce oxidative stress in neuronal cells is discussed.

Keywords:Aging, Hydrogen peroxide, Neuronal cells, Oxidative stress, Peroxyl radical.
\end{abstract}

\section{Introduction}

Free radicals were first reported in 1900 by Moses Gomberg, and linked to aging 56 years later when Denham Harman (1956) proposed that free radicals were a vital factor in the aging process (Friedman, 2011a; Lushchak, 2014). Today, the role of free radicals and oxidative stress in aging-related disease is widely recognized and largely studied. Oxidative stress-induced damage to biomolecules is a central feature of the pathology of a broad spectrum of human diseases including neurodegenerative diseases, cardiovascular diseases, diabetes, and cancer (Halliwell, 2005; Cheli and Baldi, 2011).

Oxidative stress in living cells is defined as the imbalance between the oxidants generated by cellular respiration and metabolism, and the cell's antioxidant defense system in favor of the oxidants. Reactive oxygen species (ROS) are continuously generated by the mitochondrial electron-transport chain. In healthy cells, ROS levels are under homeostatic control by the endogenous antioxidant defense system that includes biological antioxidants such as glutathione (GSH), vitamin E, and vitamin C and antioxidant enzymes including catalase, superoxide dismutase (SOD), glutathione peroxidase (GPx), and heme-oxygenase I (HO-1). Thus, oxidative stress occurs when levels of ROS generated exceed the cellular antioxidant capacity (Finkel and Holbrook,
2000; Klein and Ackerman, 2003; Cheli and Baldi, 2011).

Neuronal cells are more sensitive to oxidative stress than other cells for a number of reasons, including their high rate of oxygen consumption, which generates a significant amount of ROS, and a modest antioxidant defense. Neuronal cell membranes are also rich in polyunsaturated fatty acids (PUFAs), which makes them highly sensitive to oxidation by extracellular ROS (Friedman, 2011b).

Considering the sensitivity of neuronal cells to oxidative stress and its implication in neurodegenerative disease, many have attempted to determine the mechanism of ROS-induced oxidative damage and the protective effect of antioxidants. Such studies often use primary neuronal cells cultures or neuronal cell lines and oxidative stress is induced in vitro using oxidants such as $\mathrm{H}_{2} \mathrm{O}_{2}$ and free radical initiators as a source of peroxyl radicals. Neurotoxins such as 6-hydroxydopamine (6-OHDA) (Lopes et al., 2010) or secondary lipid peroxidation products such as aldehyde-4-hydroxy2-nonenal (HNE) (Schneider et al., 2011) have also been used to mimic the oxidative stress observed in neurodegenerative disease.

This review will focus on the use of $\mathrm{H}_{2} \mathrm{O}_{2}$ and the free radicalgenerating azo compound 2,2' - azobis (2-amidinopropane) dihydrochloride (AAPH) to induce oxidative stress in neuronal cells. The mechanisms of action and uses of both oxidants will be discussed. 
Please cite this article as:

Ben Othman and Yabe, Reviews in Agricultural Science, 3:40-45, 2015

Doi: $10.7831 /$ ras.3.40

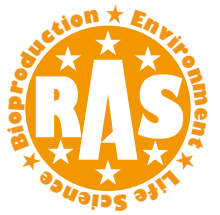

$\mathrm{H}_{2} \mathrm{O}_{2}$-Induced Oxidative Stress in Neuronal Cells

In eukaryotic organisms, ROS are continuously produced by the mitochondrial electron transport chain where molecular oxygen is reduced to $\mathrm{O}_{2}{ }^{-}$due to the escape of an active electron. As illustrated in Figure 1, the generated $\mathrm{O}_{2}{ }^{-}$is spontaneously or enzymatically converted to $\mathrm{H}_{2} \mathrm{O}_{2}$. Thereafter, $\mathrm{H}_{2} \mathrm{O}_{2}$ can be converted to $\mathrm{OH}^{\bullet}$ and $\mathrm{OH}^{-}$by accepting an electron in a reaction catalyzed by transition metal ions $\left(\mathrm{Fe}^{2+}\right.$ or $\left.\mathrm{Cu}^{+}\right)$. The generated hydroxyl radicals are highly reactive and are believed to cause significant oxidative damage. In order to prevent the formation of these harmful hydroxyl radicals, $\mathrm{H}_{2} \mathrm{O}_{2}$ is converted to water via reactions catalyzed by enzymes such as catalase and GPx (Lushchak, 2014). The intracellular concentration of $\mathrm{H}_{2} \mathrm{O}_{2}$ is therefore tightly controlled by the cellular antioxidant defense system. The homeostatic concentration of $\mathrm{H}_{2} \mathrm{O}_{2}$ ranges between 1 and $700 \mathrm{nM}$, and an intracellular concentration above $1 \mu \mathrm{M}$ is considered to induce oxidative stress (Gülden et al., 2010) .

$\mathrm{H}_{2} \mathrm{O}_{2}$ is therefore used as a model to investigate the oxidative stress mechanisms within neuronal cells. Whittemore et al. (1995) showed that exposure to low concentrations of $\mathrm{H}_{2} \mathrm{O}_{2}(10-100 \mu \mathrm{M})$ induced apoptosis of neuronal cells. Specifically, they reported that exposure to $30 \mu \mathrm{M} \mathrm{H}_{2} \mathrm{O}_{2}$ for only $3 \mathrm{~h}$ induced nuclear changes characteristic of apoptosis, including chromatin condensation, nuclear pyknosis, and fragmentation.

There is wide variation in the $\mathrm{H}_{2} \mathrm{O}_{2}$ concentration thought to be cytotoxic, with estimates ranging from 10 to $1000 \mu \mathrm{M}$. We collected estimates from recent studies that investigated $\mathrm{H}_{2} \mathrm{O}_{2}$-induced oxidative stress in PC-12 and SH-SY5Y cells; some examples are given in Table $1 . \mathrm{PC}-12$ is a rat adrenal pheochromocytoma cell line, and the human neuroblastoma SHSY5Y cell line is a cloned subline of SK-N-SH cells originally derived from a bone marrow neuroblastoma. Both cell lines are often used in studies of neurodegenerative disease, owing to their neuronal cell-like properties (Xie et al., 2010; Cheng et al., 2013). According to Gülden and co-workers (2010), differences in cell plating density contribute to the variation in $\mathrm{H}_{2} \mathrm{O}_{2}$ cytotoxic concentration reported in different studies. They showed that the short-term exposure of high-density $\mathrm{C} 6$ glioma cells in culture to high concentrations of $\mathrm{H}_{2} \mathrm{O}_{2}$ is equivalent to the long-term exposure of a low-density cell culture to a low $\mathrm{H}_{2} \mathrm{O}_{2}$ concentration. Thus, they recommended that the $\mathrm{H}_{2} \mathrm{O}_{2}$ concentration used for cytotoxicity studies be reported as $\mu \mathrm{mol} / 10^{7}$ cells or $\mu \mathrm{mol} / \mathrm{mg}$ cell protein rather than $\mu \mathrm{mol} / \mathrm{L}$. However, the cell density used for experiments is often omitted in papers, which makes it difficult to compare data obtained from different studies.

It is important to consider the role of metabolic $\mathrm{H}_{2} \mathrm{O}_{2}$ in redox

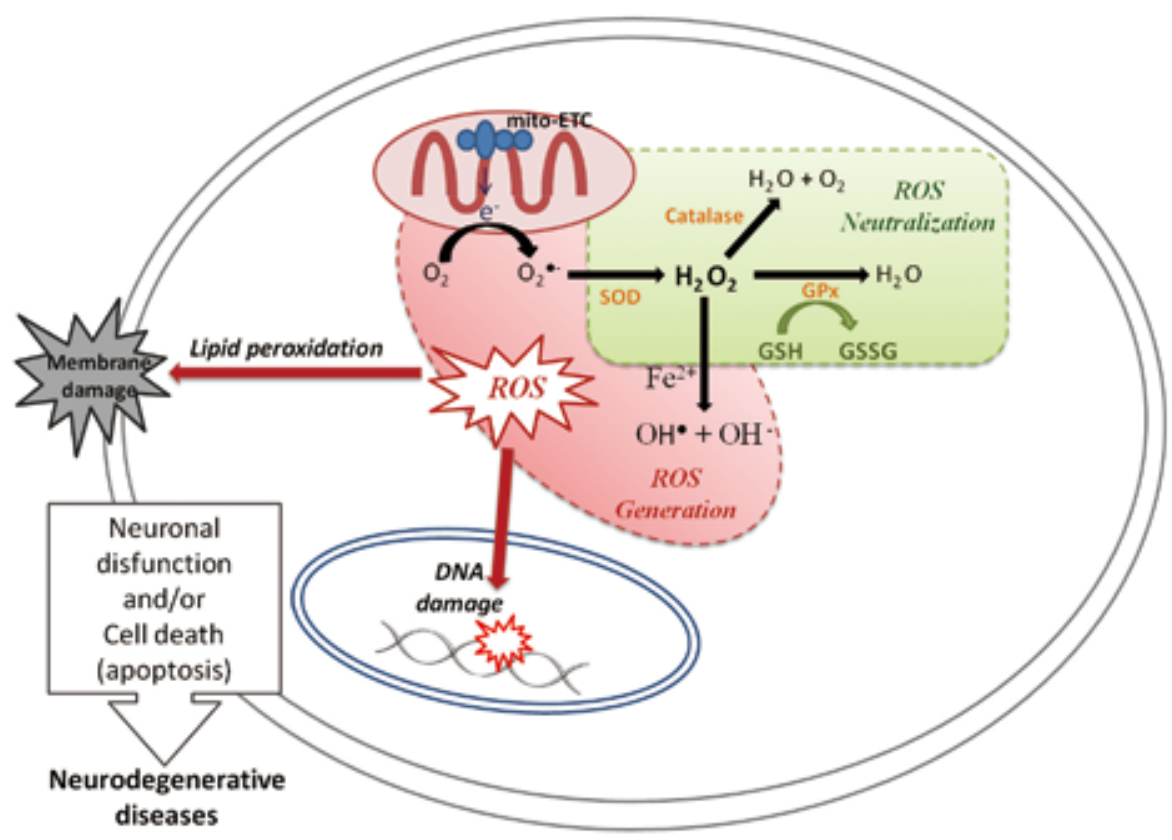

Fig.1. ROS generation and neutralization in neuronal cells and their role in neurodegenerative diseases. ROS, reactive oxygen species; mito-ETC, mitochondrial electron transport chain; SOD, superoxide dismutase; GPx, glutathione peroxidase; GSH, reduced glutathione; GSSG, oxidized glutathione. 
Table 1 Variation in $\mathrm{H}_{2} \mathrm{O}_{2}$-induced cytotoxicity in rat adrenal pheochromocytoma (PC-12) and human neuroblastoma (SH-SY5Y) cell lines.

\begin{tabular}{|c|c|c|c|c|}
\hline Cell line & $\mathrm{H}_{2} \mathrm{O}_{2}$ Concentration & $\begin{array}{c}\text { Treatment } \\
\text { duration }\end{array}$ & Cell viability & Reference \\
\hline \multirow{6}{*}{ PC-12 cells } & $100 \mu \mathrm{M}$ & $24 \mathrm{~h}$ & $\sim 50 \%$ & Jin et al. (2013) \\
\hline & $200 \mu \mathrm{M}$ & $24 \mathrm{~h}$ & $\sim 40 \%$ & Lou et al. (2012) \\
\hline & $300 \mu \mathrm{M}$ & $24 \mathrm{~h}$ & $\sim 50 \%$ & Cheng et al. (2013) \\
\hline & $300 \mu \mathrm{M}$ & $24 \mathrm{~h}$ & $\sim 60 \%$ & Pavlica and Gebhardt (2010) \\
\hline & $400 \mu \mathrm{M}$ & $24 \mathrm{~h}$ & $\sim 50 \%$ & Crispo et al. (2010) \\
\hline & $400 \mu \mathrm{M}$ & $1 \mathrm{~h}$ & $\sim 70 \%$ & Liu et al. (2011) \\
\hline \multirow{8}{*}{ SH-SY5Y cells } & $1 \mathrm{mM}$ & $16 \mathrm{~h}$ & $\sim 15 \%$ & Ju et al. (2012) \\
\hline & $1 \mathrm{mM}$ & $16 \mathrm{~h}$ & $\sim 25 \%$ & Ruffels et al. (2004) \\
\hline & $750 \mu \mathrm{M}$ & $16 \mathrm{~h}$ & $\sim 80 \%$ & Ruffels et al. (2004) \\
\hline & $200 \mu \mathrm{M}$ & $24 \mathrm{~h}$ & $\sim 70 \%$ & Nakano et al. (2011) \\
\hline & $200 \mu \mathrm{M}$ & $24 \mathrm{~h}$ & $\sim 60 \%$ & Xiao et al. (2013) \\
\hline & $200 \mu \mathrm{M}$ & $24 \mathrm{~h}$ & $\sim 50 \%$ & Zhang et al. (2007) \\
\hline & $100 \mu \mathrm{M}$ & $24 \mathrm{~h}$ & $\sim 65 \%$ & Zhang et al. (2007) \\
\hline & $100 \mu \mathrm{M}$ & $24 \mathrm{~h}$ & $\sim 40 \%$ & Suematsu et al. (2011) \\
\hline
\end{tabular}

signaling. $\mathrm{H}_{2} \mathrm{O}_{2}$ is being increasingly recognized as a messenger molecule. It is involved in signaling pathways involved in changes to cell shape, the formation of actomyosin, and the recruitment of immune cells (Sies, 2014). Oxidative stress induced by $\mathrm{H}_{2} \mathrm{O}_{2}$ was first thought to cause only lipid peroxidation, DNA and protein damage, but it is now known that $\mathrm{H}_{2} \mathrm{O}_{2}$ activates various intracellular signaling pathways closely associated with neuronal cell death and survival (Ruffels et al., 2004). The cellular response to $\mathrm{H}_{2} \mathrm{O}_{2}$ depends on its intracellular concentration: low levels (3-15 $\mu \mathrm{M})$ stimulate growth, whereas increasing concentrations induce cell growth arrest, apoptosis, and finally necrosis (at levels above $1 \mathrm{mM}$ ) (Gülden et al., 2010). The turning point between signaling and toxicity is still to be determined and may vary depending on the cell type and metabolic conditions (Saito et al., 2006; Sies, 2014). Therefore, choosing the appropriate experimental conditions when using $\mathrm{H}_{2} \mathrm{O}_{2}$ to study oxidative damage (and potential protective treatments) is paramount.

\section{AAPH-Induced Oxidative Stress in Neuronal Cells}

Azo compounds are commonly used as free radical initiators. AAPH is a hydrophilic radical initiator. As shown in Figure 2, AAPH decomposes spontaneously at $37^{\circ} \mathrm{C}$ to yield molecular nitrogen and two carbon radicals, $\mathrm{R}^{\circ}$. The generated radicals react rapidly with oxygen to form peroxyl radical $\mathrm{ROO}^{\bullet}$ (Niki, 1990; Werber et al., 2011). Peroxyl radicals were initially considered the predominant radical generated by AAPH, but Werber and coworkers (2011) recently showed by using LC-MS/MS that the predominant radical species generated by AAPH is in fact alkoxyl radical $\mathrm{RO}^{\bullet}$. Although $\mathrm{ROO}^{\bullet}$ must be produced to generate $\mathrm{RO}^{\bullet}$, the researchers postulate that it is short-lived in solution.

While AAPH has been used to induce oxidative stress in neuronal cell cultures, it is less commonly used than $\mathrm{H}_{2} \mathrm{O}_{2}$. AAPH was reported to induce the oxidation of membrane lipids and proteins (Niki, 1990). PUFAs are the most oxygen-sensitive constituents of cells, and the lipid peroxyl radicals ( $\mathrm{LOO}^{\bullet}$ ) they produce are very reactive and have been associated with the development of neurodegenerative diseases (Spiteller, 2006; Friedman, 2011a). Lipid peroxidation is involved in AAPH-induced oxidative damage in PC-12 cells, resulting in both apoptosis and necrosis, as reported by Piga et al. (2007). This study also indicated that AAPH-induced apoptosis occurs via a caspase-independent pathway, such as the mitochondrial apoptosis-inducing factor (AIF) pathway. AAPH was also reported to induce DNA damage (Kim et al., 2012) but it is unclear if such damage is directly induced by peroxyl radicals or if intermediate products are involved.

$\mathrm{Ca}^{2+}$ homeostasis is an important factor in protecting neuronal cells and preserving their functionality (Sharma et al., 2014). The treatment of synaptic plasma membranes from rat brains with AAPH in vitro was shown to inactivate the plasma membrane $\mathrm{Ca}^{2+}$ ATPase (PMCA) by PMCA protein oxidation and aggregation (Zaidi and Michaelis, 1999). Thus, loss of $\mathrm{Ca}^{2+}$ homeostasis may contribute to AAPH-induced neuronal cell death.

Unlike $\mathrm{H}_{2} \mathrm{O}_{2}$, which can be transported across the cell membrane via simple diffusion or aquaporins (Sies, 2014) and induce different signaling pathways, AAPH generates peroxyl and alkoxyl radicals that react with cell membrane components (primarily PUFAs), 


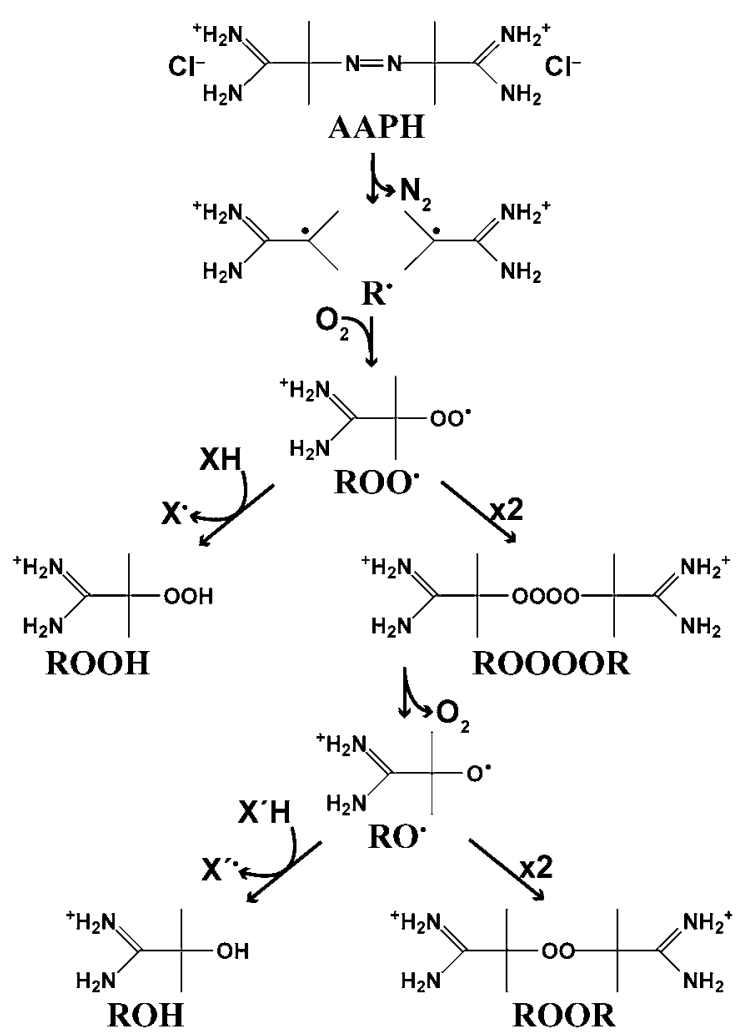

Fig.2. AAPH thermal degradation scheme. This figure is a simplified version of the reaction scheme published by Werber et al. (2011). $\mathrm{XH}$ and $\mathrm{X}$ 'H refer to hydrogen donors in solution.

initiating an oxidative chain reaction resulting in cell death.

\section{Conclusion}

Since being associated with aging-related diseases, oxidative stress has been extensively studied with a view to developing preventive and curative treatments for such diseases. However, the exact role of ROS in inducing oxidative damage is still not completely elucidated which makes it more difficult to interpret the precise mechanism of action of antioxidants in protecting cells against oxidative stress.

As reviewed here, oxidative stress depends on the nature of the oxidant and its concentration in the cell. Lushchak (2014) classified oxidative stress based on its intensity, ranging from basal oxidative stress to high-intensity oxidative stress. He proposed that this classification be used to describe experimental data in oxidative stress studies. Moreover, in a more recent commentary, Sies (2015) emphasized the importance of specifying the exact molecular condition used to induce oxidative stress, as the cell response depends on the nature of the oxidant, its concentration, and the cell culture conditions.

Further studies regarding the interactions between ROS and cell components, and the mechanisms of the resulting cellular signaling and damage, are crucial for the development of novel antioxidant therapies for aging-related diseases.

\section{References}

Cheli F and Baldi A (2011) Nutrition-based health: cell-based bioassays for food antioxidant activity evaluation. J. Food Sci., 76: 197-205.

Cheng B, Lu H, Bai B and Chen J (2013) D- $\beta$-Hydroxybutyrate inhibited the apoptosis of PC12 cells induced by $\mathrm{H}_{2} \mathrm{O}_{2}$ via inhibiting oxidative stress. Neurochem. Int., 62: 620-625.

Crispo JAG, Piché M, Ansell DR, Eibl J, Tai IT, Kumar A, Ross GM and Tai TC (2010) Protective effects of methyl gallate on $\mathrm{H}_{2} \mathrm{O}_{2}$-induced apoptosis in PC12 cells. Biochem. Biophys. Res. Commun., 393: 773-778.

Finkel T and Holbrook NJ (2000) Oxidants, oxidative stress and the biology of aging. Nature, 408: 239-247. 
Friedman J (2011a) The role of free radicals in the nervous system. In: Oxidative Stress and Free Radical Damage in Neurology (Gadoth N and Göbel HH, ed.). pp. 1-13. Humana Press.

Friedman J (2011b) Why is the nervous system vulnerable to oxidative stress? In: Oxidative Stress and Free Radical Damage in Neurology (Gadoth N and Göbel HH, ed.). pp. 19-26. Humana Press.

Gomberg M (1900) An instance of trivalent carbon: triphenylmethyl. J. Am. Chem. Soc., 22: 757-771.

Gülden M, Jess A, Kammann J, Maser E and Seibert H (2010) Cytotoxic potency of $\mathrm{H}_{2} \mathrm{O}_{2}$ in cell cultures: Impact of cell concentration and exposure time. Free Rad. Biol. \& Med., 49: 1298-1305.

Halliwell B (2005) Free radicals and other reactive species in disease. In: Encyclopedia of Life Science. John Wiley \& Sons Ltd., Chicheste.

Harman D (1956) Aging: a theory base on free radical and radiation chemistry. J.Gerontol., 11: 298-300.

Jin MM, Zhang L, Yu HX, Meng J, Sun Z and Lu RR (2013) Protective effect of whey protein hydrolysates on $\mathrm{H}_{2} \mathrm{O}_{2}$-induced PC12 cells oxidative stress via a mitochondria-mediated pathway. Food Chem., 141: 847-852.

Ju H-Y, Chen S C, Wu K-J, Kuo H-C, Hseu Y-Cg, Ching H and Wu C-R (2012) Antioxidant phenolic profile from ethyl acetate fraction of Fructus Ligustri Lucidi with protection against hydrogen peroxide-induced oxidative damage in SH-SY5Y cells. Food Chem. Toxicol., 50: 492-502.

Kim KN, Cha SH, Kim EA, Kang MC, Yang HM, Kim MJ, Yang HY, Roh SW, Jung WK, Heo SJ, Kim D, Jeon YJ and Tatsuya O (2012) Neuroprotective effects of Nannochloropis oculata against AAPH-induced oxidative DNA damage in HT22 cells. Int. J. Pharmacol., 8: 527-534.

Klein JA and Ackerman SL (2003) Oxidative stress, cell cycle, and neurodegeneration. J. Clin. Invest., 111: 785-793.

Liu Q, Kou JP and Yu BY (2011) Ginsenoside Rg1 protects against hydrogen peroxide-induced cell death in PC12cells via inhibiting NF-kB activation. Neurochem. Int., 58: 119-125.

Lopes FM, Schröder R, Conte Da Frota Junior ML, Zanotto-Filho A, Müller CB, Pires AS, Meurer RT, Colpo GD, Gelain DP, Kapczinski F, Moreira JCF, Fernandes MC and Klamt F (2010) Comparison between proliferative and neuron-like Sh-SY5Y cells as an in vitro model for Pakinson disease studies. Brain Res., 1337: 85-94.

Lou H, Jing X, Ren D, Wei X and Zhang W (2012) Eriodictyol protects against $\mathrm{H}_{2} \mathrm{O}_{2}$-induced neuron-like PC12 cell death through activation of Nrf2/ARE signaling pathway Neurochem. Int., 61: 251-257.

Lushchak VI (2014) Classification of oxidative stress based on its intensity. EXCLI J., 11: 922-937.

Niki E (1990) Free radical initiators as source of water- or lipidsoluble peroxyl radicals. Meth. Enzymol., 186: 100-108.

Pavlica S and Gebhardt R (2010) Protective effects of flavonoids and two metabolites against oxidative stress in neuronal PC12 cells. Life Sci. 86: 79-86.

Piga R, Saito Y, Yoshida Y and Niki E (2007) Cytotoxic effects of various stressors on PC12 cells: Involvement of oxidative stress and effect of antioxidants. Neurotoxicology, 28: 67-75.

Ruffels J, Griffin M and Dickenson JM (2004) Activation of ERK1/2, JNK and PKB by hydrogen peroxide in human SHSY5Y neuroblastoma cells: role of ERK1/2 in $\mathrm{H}_{2} \mathrm{O}_{2}$-induced cell death. Eur. J. Pharm., 483: 163-173.

Saito Y, Nishio K, Ogawa Y, Kimata J, Kinumi T, Yoshida Y, Noguchi N and Niki E (2006) Turning point in apoptosis/necrosis induced by hydrogen peroxide. Free Rad. Res., 40: 619-630.

Sharma MK, Jalewa J and Hölscher C (2014) Neuroprotective and anti-apoptotic effects of liraglutide on SH-SY5Y cells exposed to methylglyoxal stress. J. Neurochem., 128: 259-471.

Schneider L, Giordano S, Zelickson BR, Johnson MS, Benavides GA, Ouyang X, Fineberg N, Darley-Usmar VM and Zhang J (2011) Differentiation of SH-SY5Y cells to a neuronal phenotype changes cellular bioenergetics and the response to oxidative stress. Free Rad. Biol. \& Med., 51: 2007-2017.

Sies H (2014) Role of metabolic $\mathrm{H}_{2} \mathrm{O}_{2}$ generation: Redox signaling and oxidative stress. J. Biol. Chem., 289: 8735-8741.

Sies H (2015) Oxidative stress: a concept in redox biology and medicine. Redox Biol., 4: 180-183.

Spiteller G (2006) Peroxyl radicals: Inductors of neurodegenerative and other inflammatory diseases. Their origin and how they transform cholesterol, phospholipids, plasmalogens, polyunsaturated fatty acids, sugars, and proteins into deleterious products. Free Rad. Biol. \& Med., 41: 362-387.

Suematsu N, Hosoda M and Fujimori K (2011) Protective effects of quercetin against hydrogen peroxide-induced apoptosis in human neuronal SH-SY5Y cells. Neurosci. Lett., 504: 223-227.

Taki-Nakano N, Ohzeki H, Kotera J and Ohta H (2011) Cytoprotective effects of 12-oxo phytodienoic acid, a plantderived oxylipin jasmonate, on oxidative stress-induced toxicity in human neuroblastoma SH-SY5Y cells. Biochim. Biophys. Acta, 1840: 3412-3422.

Werber J, Wang YJ, Milligan M, Li X and Ji JA (2011) Analysis of 2,2'-azobis (2-amidinopropane) dihydrochloride degradation and hydrolysis in aqueous solutions. J. Pharmacol. Sci., 100: 3307-3315.

Whittemore ER, Loo DT, Watt JA and Cotman CW (1995) A detailed analysis of hydrogen peroxide-induced cell death in primary neuronal culture. Neuroscience, 67: 921-932.

Xiao Z, Huang C, Wu J, Sun L, Hao W, Leung LK and Huang J 
(2013) The neuroprotective effects of ipriflavone against $\mathrm{H}_{2} \mathrm{O}_{2}$ and amyloid beta induced toxicity inhuman neuroblastoma SHSY5Y cells. Eur. J. Pharmacol., 721: 286-293.

Xie H, Hu L and Li G (2010) SH-SY5Y human neuroblastoma cell line: in vitro cell model of dopaminergic neurons in Parkinson's disease. Chin. Med. J., 123: 1086-1092.

Zaidi A and Michaelis ML (1999) Effect of reactive oxygen species on brain synaptic plasma membrane $\mathrm{Ca}^{2+}$-ATPase. Free Rad. Biol. \& Med., 27: 810-821.

Zhang L, Yu H, Sun Y, Lin X, Chen B, Tan C, Cao G and Wang Z (2007) Protective effects of salidroside on hydrogen peroxideinduced apoptosis in SH-SY5Y human neuroblastoma cells. Eur. J. Pharmacol., 564: 18-25. 